\title{
Economic and Cultural Peripheralization in the Eurozone
}

\author{
Antonio Luigi Paolilli \\ University of Salento, Lecce, Italy \\ Email: apaolilli@alice.it
}

Received September $5^{\text {th }}, 2013$; revised October $11^{\text {th }}, 2013$; accepted November 22 $2^{\text {nd }}, 2013$

\begin{abstract}
Copyright ( 2014 Antonio Luigi Paolilli. This is an open access article distributed under the Creative Commons Attribution License, which permits unrestricted use, distribution, and reproduction in any medium, provided the original work is properly cited. In accordance of the Creative Commons Attribution License all Copyrights (C) 2014 are reserved for SCIRP and the owner of the intellectual property Antonio Luigi Paolilli. All Copyright (C) 2014 are guarded by law and by SCIRP as a guardian.
\end{abstract}

In this paper, we will discuss the reasonableness of the decision by Italy and other southern and western EU states to become members of the eurozone. We will also discuss whether this economic choice can be socially and culturally sustainable in a Europe characterized by cultures which, despite their shared substratum, are in competition with each other.

Keywords: Peripheralization; Social Cohesion; Economic History

\section{Introduction}

In 1992 when Italy left the EMS with a great devaluation, above all compared to the Deutsche mark ${ }^{1}$, it was not alone, because the pound sterling also withdrew from the EMS. The United Kingdom, however, did not join the eurozone, unlike Italy and other outlying states of the EU. In this paper, we will discuss the reasonableness of the decision by Italy and other southern and western EU members, in the light of the comments made in some recent papers. We will also examine the issue of whether this economic choice can be socially and culturally sustainable in a Europe characterized by cultures which, despite their shared substratum, are in competition with each other.

\section{Restrictive Policies, Finance and Peripheralization Processes}

The years following the outbreak of the Global Financial Crisis have been characterized in most eurozone states, and above all in the so called PIIGS, by a great acceleration of austerity policies consisting, besides further deregulation of the labor market, essentially of a reduction of public spending and in an increase in taxes, in order to achieve a balanced public budget. In the view of supporters of austerity, even though these fiscal policies were brought in during a crisis, and therefore even though they cause a worsening of the recession, they should in the long term lead to a lasting economic recovery. This approach has aroused radical criticism. It has been argued in fact that austerity policies not only herald recession, but they are also ineffective and even produce the opposite effect to the purpose of reducing the public debt/GDP ratio (Forges Davanzati, 2013; Cesaratto \& Pivetti, 2012), due to the consequent recessive spiral which reduces the tax base.

These criticisms, however, seem feeble to the advocates of

\footnotetext{
${ }^{1}$ Amato's Government took the decision to get of EMS and to devalue the lira only after a strong, enduring and by then unsustainable attach of the market.
}

austerity who, above all in the German area, believe that the differences among the performances of the various EU member states are essentially caused by the different approaches taken by governments and even by the populations, which can be divided, in their opinion, into "cicadas" (spenders) and "ants" (savers).

It has been shown, however (Paolilli, 2011a; Paolilli \& Pollice, 2011b) that the peripheralization processes are mostly due to geographical factors, stressing moreover the role that monetary and financial institutions have in territorial dynamics. According to this viewpoint, the financialization of the economy, into the broader scenario of globalization, can reinforce cumulative processes which widen the pre-existing territorial gaps. Specifically, it has been shown, by means of a mathematical model, that disadvantaged regions can end up financing, at least indirectly, the economic activities of those areas from which they have received direct investments. In fact, when a growth process begins in a region, it tends to extend to other areas, but the outcome of the investments in those areas is essentially dependent on some of their geographical and cultural characteristics. There are in fact various types of peripheral countries, which can be grouped essentially into two categories. The real peripheries (which we can call peripheries of type A), are usually near the central areas (but not close enough to be progressively absorbed by them). They experience the economic and cultural influence of central areas, also due to workers' emulative tendencies, but they could never reach the same levels of productivity and welfare (the comparison South-North of Italy is a good example of this scenario). In fact we can assume that productivity is also a function of the worker's effort. It must be considered that the smaller the gap between the actual wage and the target wage, the greater the effort, and that in the mind of workers of type A peripheries the target wage can be the same as that perceived by workers in central areas. Therefore, given the lower productivity of the peripheral regions (due to the fact that these areas are less interested by cumulative processes of economic growth), we can deduce that in type A peripheries 
there is a vicious circle: low productivity, low wages; little effort, low productivity. In contrast, the peripheries which are separated from the central areas by means of physical, political or cultural barriers, and which we will call peripheries of type $B$, even though they may experience economic dependence, can easily overcome it if they have adequate physical and human resources.

Besides showing the existence of a natural conflict between financers and producers, in which finance seems to have a natural aptitude to absorb industrial profits, the model in the work cited above also shows that interest rates in peripheral areas tend to be higher than in central areas. This phenomenon hinders the local enterprises which, at least in the initial phase of their growth, are small and therefore not able to easily obtain direct financing. The model, then, explains the prevalence of indirect financial flows (i.e. carried out through banks) from peripheral regions to central areas, flows which tend to counterbalance the diffusive effects of direct investments from central areas towards peripheral ones. The counterbalancing effect of indirect flows, moreover, is particularly deleterious for type A peripheries. These areas are often bypassed by direct funding, because the geographic and cultural proximity to central areas tends to raise the target wages, reducing effort and therefore labor productivity, if real wages are significantly lower than target wages. The vicious circle we have seen above is then reinforced by the financial dynamics: the difference between the interest rate applied in central and peripheral areas, particularly type A (but also in type B, at least while they remain on the periphery), consolidate the processes of cumulative causation which increase the difference in productivity between the two types of regions.

The theoretical considerations we have explained above are corroborated by what happens in the real world. As noted by Spratt (2009: p. 67), the liberalization started under Reagan's presidency caused a much higher interest rate rise than expected, above all in poor countries. Spratt also points out that, unexpectedly, i.e. contrary to the provisions of orthodox economic theory, many studies have shown that growth of real interest rates has often led to a fall in accumulation rates. Examining the financial flows in the Nineties and early years of this millennium, first, the author observes that, again contrary to the forecasts by advocates of liberalization, they have not followed a linear trend, but cyclical behavior, with an alternation of growths and declines. Moreover, with the exclusion of direct financing, financial flows between developed countries and emerging areas have not only fluctuated, but have periodically changed direction too, resulting in a balance showing a net flow from developing regions to developed areas. Furthermore, we must stress that the financial flows studied by Spratt are those between developed regions and emerging areas, which can be classified as type B peripheries. As we will also see below, the dynamics are presumably even more pernicious for type A peripheries.

\section{Europe before the Integration: A Singular Case of Cooperation and Competition}

From the discussion above we can deduce that many problems may derive by the increasing connectivity of the world, if not adequately regulated.

As far as Europe is concerned, these problems are exacerbated by the adoption of a single currency, which is not coun- terbalanced by the existence of a single state. National currencies, in fact, were a sort of barrier amongst the various economies of the Union, without, however, greatly reducing their trade with each other. Trade was intense but it was adjusted by the rising and falling of national currencies. The resulting situation, therefore, can be called an optimal combination of cooperation and competition.

The view that productivity can be higher if there is a balanced combination of competition and cooperation is underlined by Diamond (2006, 1997: pp. 357, 360-361). It has been noted, for example, that technological progress, in modern industrial companies, is favored by a balanced mix of competition and circulation of information (which may be regarded as a form of cooperation). Big companies which are hierarchically organized seem less efficient than others, equally large but composed of relatively independent units competing with each other, but not so much as to prevent information circulating among them.

With regard to economic and political systems, it has been observed (Paolilli \& Pollice, 2011a), by means of a mathematical model, that the greater the competition and/or the less the cooperation and emulation, the lower the number of EPS (economic-political systems) in a geographical area. The model also shows that technological progress allows an EPS to increase its area of influence, reducing the economic role of the EPS that are unable to rapidly renew their technological level or to adopt strategies to diversify their production, specializing in the use of other resources.

Since the Middle Ages Europe has been characterized by a singular combination of cooperation and competition. Cooperation was based on a common (Christian) culture, also favored by the use of Latin by the educated and the clergy, while competition arose from the fact that it was difficult for societies whose economy was not based on sea trade as in Ancient Times (due to Islamic and other invasions in the Mediterranean basin), to unify in a single EPS. According to recent studies (Paolilli \& Pollice, 2011a), this combination has probably been the main factor which allowed Europe, rather than other EPS, like China or the Roman empire, to undertake the development towards Modernity (see also Scheidel, 2007; Paolilli, 2008). It is interesting the make a comparison with China which, apart some short periods, was always more cohesive than Europe. It was precisely for this reason that, although $15^{\text {th }}$-century China was equipped with technologies which would allow it to undertake the development towards Modernity (its enormous fleet sailed and explored the Indian ocean), it only took a political upheaval led by a few individuals at the top of the institutions to cause the total abandonment of expansionist policy and the isolation of that great nation (Diamond, 2006, 1997: p. 318).

The mix of cooperation and competition, then, enabled Europe to evolve towards Modernity because of the application of innovations was favored by the ease of disseminating ideas and at the same time it was necessitated by the fact that the continental EPS were competing with each other.

This, of course, does not necessarily mean that the optimal dimension for the European countries in the current global competition is still that of the single nation.

We must consider, in fact, that increasing globalization, favored by the speed of communications and the lowering of their costs, has changed the scale of competition from a regional or sub-continental context to a global one. In the present time, EPS the size of China do not risk being isolated. Their economic systems are in fact increasingly interconnected with the 
others and are therefore stimulated to a competition and cooperation that are almost irreversible.

With regard to Europe, the process of integration and cooperation was increased by the establishment after the Second World War of an area of free trade, eliminating the possibility of wars, without however reducing that degree of competition which, together with cooperation, as we have seen above, is the main factor of progress. The single states of the European Common Market, in other words, cooperated more than in any other previous periods, but their single economic systems were mutually protected against excessive competition which could lead to centralization and therefore peripheralization due to monetary barriers.

The establishment of the EMS (March 13, 1979) had already reduced the amplitude of such barriers, further facilitating trade thanks to a careful control of exchange rates between EU currencies. This control, however, ended up replacing a series of fluctuations in currency exchange rates, which could have regulated the trade relations between the countries, with one great final currency crisis which broke up the EMS ${ }^{2}$.

The introduction of the Euro was not accompanied by the creation of a central government to implement a significant redistribution of income. There continue to exist many states responsible for administering public affairs without however being able to issue currency while the monetary barriers between the EU Economic-Political Systems that adopted the euro have been demolished, creating a kind of "monopoly game" between the same economies. This has produced a concentration of financial resources, and therefore also of real resources, in the hands of a few and of the central areas of the Union.

The phenomenon of concentration has not been stressed by the mainstream economists, but it has been widely discussed by economic geographers, from the "cumulative causation" of Myrdal (1957) to the "New Economic Geography” of Krugman (1991, 1998). The tendency to concentration, moreover, has also been observed in other scientific contexts.

Almost every branch of science in fact recognizes the relevance of so-called "power law", according to which it can be observed that in nature the most diverse phenomena, like the importance of rivers and stars, have a negative exponential relationship with their size ${ }^{3}$. This phenomenon has been observed also in the concentration of wealth (in all the social and political contexts), where it takes the name of Pareto distribution (see Mandelbrot, 1963), contradicting the opinions of those who think that market forces will naturally generate an optimal and even equitable distribution of resources.

\section{Peripheries: The Cases of East Germany and South of Italy}

With regard to the differences between the economic systems of Northern Europe and the Mediterranean European states, it

\footnotetext{
${ }^{2}$ It has been argued that in the years following the collapse of the EMS, in spite of the devaluation of the Italian lira, there was a decrease in Italian share of European GDP and of European and world exports. This is not true if we consider per capita revenue and exports, i.e. if we take into account the reduction of the relative weight of the Italian population. Per capita exports, for example, between 1992 and 2001 increased by 42\% in Italy, while in France, Germany and the USA they increased, respectively, only by $34 \%$ $40 \%$ and $37 \%$ (Faini, 2003).

${ }^{3}$ It was the application of power law (Buchanan, 2008, pp. 183-184) that allowed researchers to verify that the furrows excavated on Mars are actually relics of ancient basins and therefore on that planet there were once considerable quantities of watery liquid.
}

has often been stressed that the latter need to comply with the former, in the belief that their failures derive above all from bad economic policies and bad habits, disinclined to austerity. We have been given, as an example to follow, the case of the unification of Germany, which would experience a rapid convergence between its East and West parts, following the reunification process which started in 1989.

In actual fact it is a rather interesting case because, unlike the cases of Portugal, Greece, Ireland and Spain, it is not related to a whole state, but to a part of it, and it is therefore more comparable to the Italian situation, historically characterized by the North-South gap. If we consider, moreover, that East Germany was annexed to West Germany and that it has suffered the political and economic hegemony of the latter, the similarity with the case of Southern Italy is even stronger: East Germany, like Southern Italy, can be defined a type A periphery.

The recent economic history of East Germany, however, is rather different from that of Southern Italy ${ }^{4}$. Unlike the latter, in fact, before the Second World War East Germany had one of the most advanced industrial systems in the world and its per capita GDP was higher than that of the western part of Germany. Moreover, besides being the seat of the political capital, East Germany was larger than it is now and was at the centre of important trade with the Slav countries. After the war, however, membership of the CMEA deteriorated the product competitiveness of East Germany and on re-entry into a market system, this caused such serious difficulties of adaptation that the survival of many businesses was threatened. To carry out the realignment process in East Germany, as in the Italian case, an "extraordinary intervention” was made. However, while in Italy this intervention interested large-scale industry, in Germany it covered mainly small and medium-size enterprises. East Germany suffered a dramatic initial depression caused, in the opinion of many observers, by the decision to achieve economic union as quickly as possible and above all to impose an equal exchange rate between the Western and Eastern mark. The latter, even though it was difficult to determine its actual value, given the great differences between the two economic and social systems, was much weaker than the former (Burker, 2009). Nevertheless the eastern regions have made great progress towards economic integration with West Germany.

It should be noted, however, that since 2004, due to the accession of several Eastern European states, East Germany, unlike southern Italy, is no longer a peripheral area, at least from a strictly geographic point of view (moreover, unlike Southern Italy, it is the seat of the country's political center). In fact in recent years, perhaps as a result of the increased centrality of the area, a further convergence of per capita incomes of the "two Germanies" seems to be underway.

However, unlike most regions of southern Italy, almost all the regions of East Germany have experienced a significant reduction of population, both in relative terms (if compared to the rest of Germany), and in absolute terms (see Figures 1 and 2). East Germany, in other words, has not increased its wealth significantly, but has rather divided it among fewer people. This phenomenon is illustrated, with regard to the demographic trends and for the period 1989-2004, by Figure 1. For the period 2004-2008 the thematic map of Figure 2 shows the relative variations of population at level NUTS 2 (regional level). The graph in Figure 3 shows instead the changes in productiv-

\footnotetext{
${ }^{4}$ About this topic see also C. Vita (2006-2007), pp. 87-92.
} 
ity in Germany's eastern regions, expressed in percentage terms compared to that of the western regions. We can easily note that productivity, after a fall following the unification, quickly recovered and progressively but more and more slowly approached the productivity of the western regions, without reaching it. Figure 4 compares per capita income rate of the eastern regions with that of the western parts of Germany. It is interesting to examine, lastly, the graph in Figure 5, which shows the relative performance (compared to the western part of Germany) of East Germany's GDP. In this case too the initial fall and the later recovery are clearly visible. We can see, however, that the recovery of the global GDP, unlike the per capita GDP, almost completely stops after the mid-1990s, remaining on significantly lower values than those before unification. Clearly this is due to the population reduction of Eastern Germany: the East Germany resulting after the integration process is a demographically a relatively smaller one, although, at the same time, characterized by greater per capita income.

Southern Italy, instead, has continued to be a real periphery. Moreover, it has been experiencing this state for a considerably longer time than East Germany and has therefore already suffered large scale migration in the past. However, it should be noted that migration, this time concerning skilled workers above all, seems to be again affecting not only southern Italy but also the whole of Italy, which will perhaps start to assume a peripheral status in its entirety.

\section{UE, Nationalities and Social Cohesion}

From the discussion above we can deduce that if on the one hand it seems unrealistic that the single national European states can continue to play a decisive role in the global scenario, on the other hand it is clear that the adoption of a single currency, without appropriate redistributive measures and indeed in combination with restrictive policies, is generating a recession so marked that it is pushing many European states toward stagnation and economic, social and in some cases even cultural decline. In fact we must not forget that the states which are members of EU are essentially nations, with thousands of years of history, albeit with a common cultural substratum. The economic differences among the EU member states cannot be bridged, if instead of the competitive evaluations and public interventions (welfare) of the past, the only strategy used is deflationary policies which definitely generate migration causing population depletion and the reduction of the political weight of entire nationalities. Inter-European migrations cannot be compared to those concerning single-nation states. What makes a cohesive society is in fact a particular human aptitude: Benthamian altruism. In humankind, in fact, both groups and individuals are vehicles of selection, the former due to Benthamian

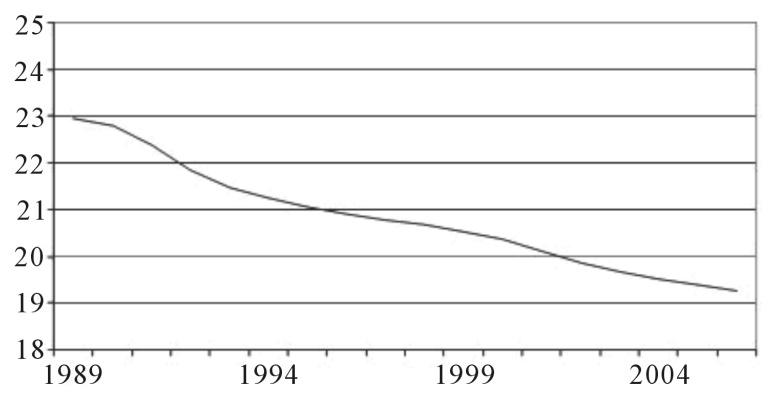

Figure 1.

Evolution of the relative weight of the eastern regions on the Germany population in the period 1989-2006 (\% values). Source: Martinez Oliva, 2009. In the work of Oliva the percentages of the Eastern Germany population erroneously refer to the Western Germany population alone.

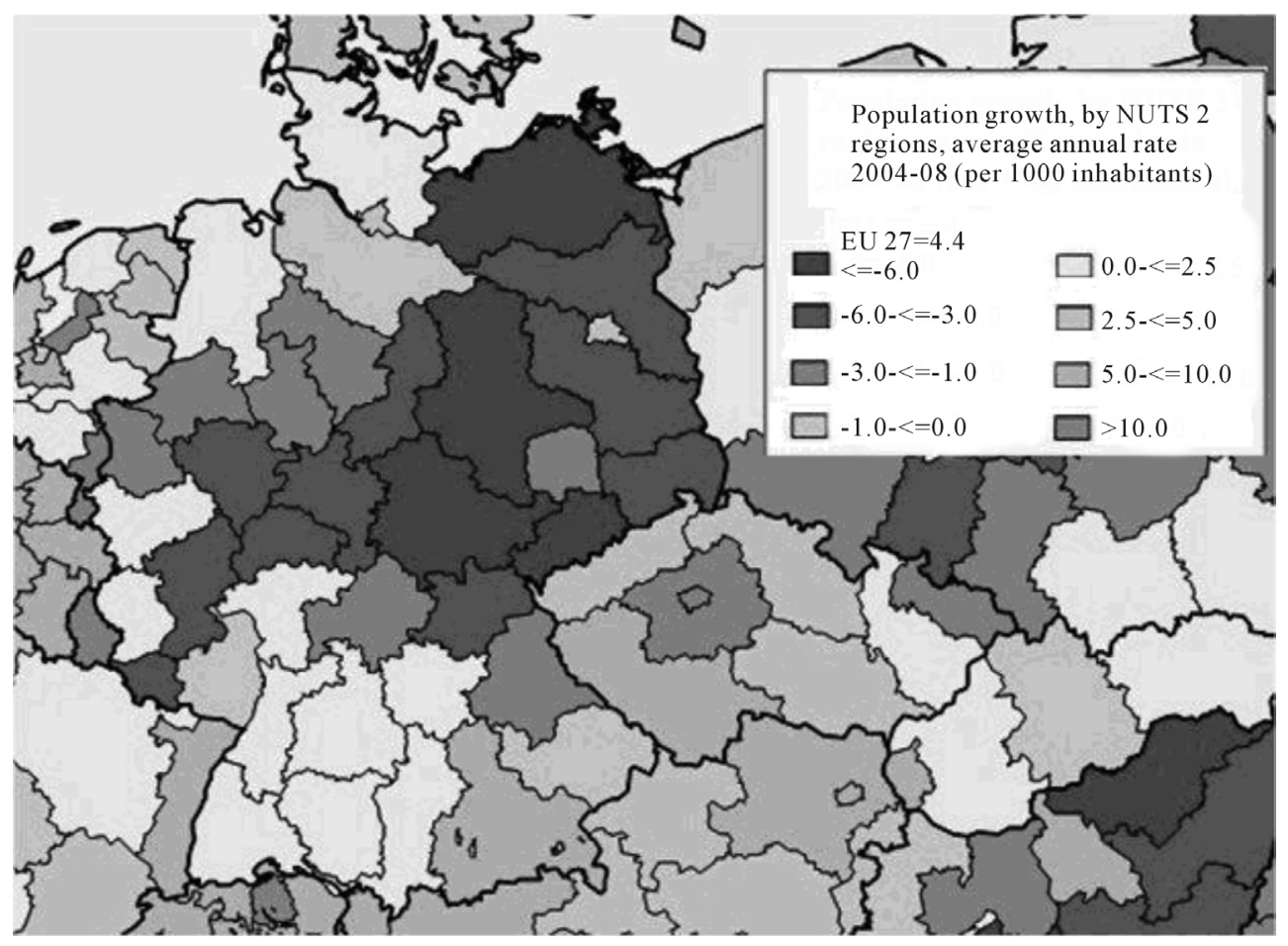

Figure 2.

Relative variations of the population in the regions (Nuts2) of Germany in the period 2004-2008. Source: Eurostat. 


\section{A. L. PAOLILLI}

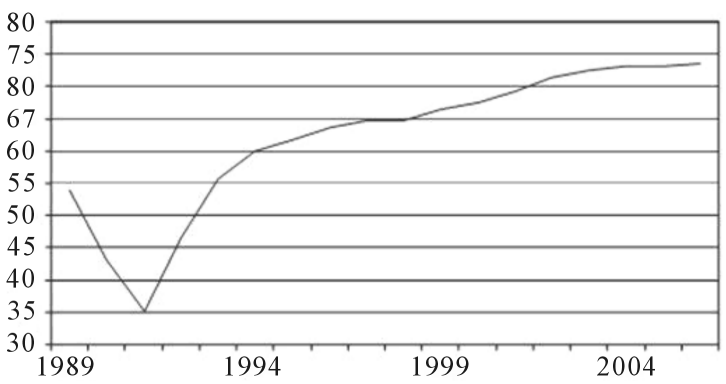

Figure 3.

Evolution of the productivity level in East Germany and West Germany in the period 1989-2006 (\% values). Source: Martinez Oliva, 2009.

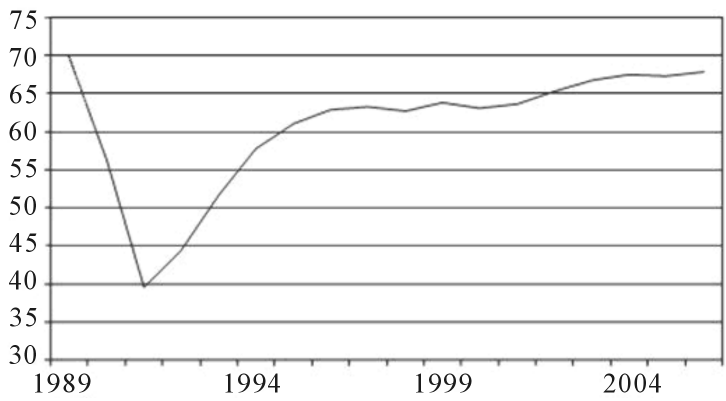

Figure 4.

Evolution of the per capita GDP of East Germany and West Germany in the period 1989-2006 (\% values). Source: Martinez Oliva, 2009.

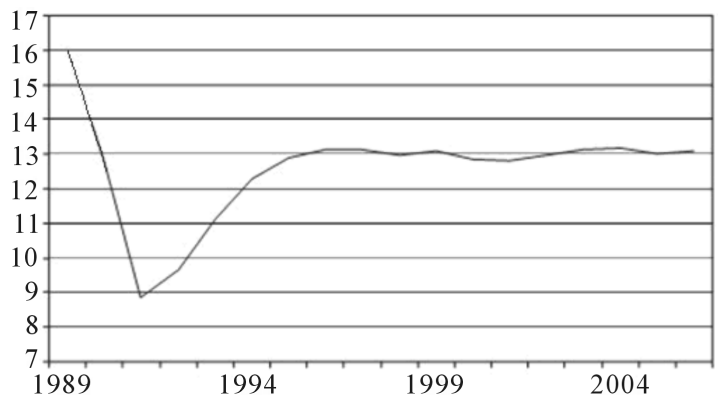

Figure 5.

Evolution of the weight of the eastern regions in the German GDP in the period 1989-2006 (\% values). Source: Martinez Oliva, 2009.

altruism, which is directed toward the group ${ }^{5}$, therefore favoring its cohesion (Paolilli, 2011b), while the individual is related to a combination of selfishness and "binary altruism", which is directed towards single humans (Paolilli, 2011b; see also Biavati, Sandri, \& Zarri, 2002; Forges Davanzati, \& Paolilli, 2004).

Benthamian altruism requires, as a priority, an identification in the group and this identification, of course, is much easier the more the individuals share cultural, economic, social and also territorial elements.

A European Union characterized by many nationalities cannot work if it is based on a structure which, to sustain itself, requires continual sacrifices which, moreover, do not seem to serve the collective well-being but instead, in deference to du-

${ }^{5}$ The group, naturally, includes the agent, who sees himself as an element of the group. bious economic theories, feed financial interests whose productivity for the whole community is unproven (on this, see Forges Davanzati, 2013). Eurozone countries must manage the apparatus of their public administration without monetary sovereignty. Therefore especially those who are economically and/ or politically weaker, end up either being subject to financial authorities like those, not democratically elected (and whose goals may differ from those of the majority of the population), or strongly influenced by the stronger political (and national) entities.

All this, in the long run, could cause a decline in identification with the EU, with political and social consequences. In fact social inequality tends to encourage behaviors which undermine the institutions both in those who profit from this inequality and, of course, in those who lack power and wealth (Glaeser \& Shleifer, 2002; Glaeser, Scheinkman, \& Shleifer, 2003; see also Buchanan, 2008: pp. 200-203). Moreover, when there is a moral distance between benefactors and beneficiaries (in the sense that the latter are not seen by the former as members of their group), the benefactors' willingness to act unselfishly depends more on considerations of effectiveness (Anen, 2007). In other words, individuals no longer continue to act unselfishly towards strangers if they think that their actions are ineffective, unlike the case in where emotional proximity is more intense and there is therefore less rationality (pushing behaviors which are apparently less rational but that generate a social cohesion which is at the basis of human societies).

\section{Conclusion}

In the light of the considerations that we have done above, we can conclude that it seems difficult to build a truly unified and democratic Europe starting from a monetary union. Then it would be more appropriate to build a Europe that is unified in some respects (e.g. with centralization of government spending for some strategic branches of the Public Administration), but consist of EPS that are more autonomous from the economic point of view, and therefore be able to implement fiscal policies. In other words, to make an analogy with the banking system, Europe should be set up not on the German model of universal bank, which operates in any monetary and financial field, but on that of the multi-purpose group, in which a central management with strategic functions co-exists with many peripherals which are almost independent from each other and that operate in the specific fields in which they are specialized.

As we have seen above, in fact, a careful combination of cooperation and competition is what has allowed not only European EPS, but also successful companies to grow and prosper.

\section{Acknowledgements}

I thank Guglielmo Forges Davanzati (University of Salento) for some useful suggestions.

\section{REFERENCES}

Anen, C. (2007). Neural correlates of economic and moral decision-making. http://thesis.library.caltech.edu/1561/

Biavati, M., Sandri, M., \& Zarri, L. (2002). Preferenze endogene e dinamiche relazionali: Un modello coevolutivo (Endogenous preferences and relational dynamics: A coevolutionary model). In P. L. Sacco, \& S. Zamagni (Eds.), Complessità relazionale e comportamento economico (Relational complexity and economic behavior) (pp. 431- 


\section{A. L. PAOLILLI}

485). Bologna, IL: Mulino.

Buchanan, M. (2008). L'atomo sociale. Il comportamento umano e le leggi della fisica, Milan, Mondadori, Italian edition of The Social Atom (2008).

Burker, M. (2009). The Economic unification of Germany, L'Arengo del viaggiatore (The arengo of the traveler), Section Economia $e$ Mercati (Economics and markets), 64.

Cesaratto, S., \& Pivetti, M. (2012). Oltre l'austerità (beyond austerity), E-book published in Micromega on-line.

Diamond, J. (2006). Guns, germs, and steel. The fates of human societies. New York: W. W. Norton \& Company.

Forges Davanzati, G. (2013). Le politiche di austerità: Un'Analisi critica (Austerity policies: A critical analysis). MarxXXI. www.marx21.it

Forges Davanzati, G., \& Paolilli, A. L. (2004). Altruismo, scambi e sviluppo economico (Altruism, trade and economic development). In L. Tundo Ferente (Ed.), La responsabilità del pensare (The responsibility of thought) (pp. 289-307). Naples: Liguori Editore.

Glaeser, E. L., \& Shleifer, A. (2002). The Injustice of Inequality, NBER Working Papers 9150. National Bureau of Economic Research, Inc.

Glaeser, E. L., Scheinkman, J., \& Shleifer, A. (2003). The injustice of inequality, Journal of Monetary Economics, 50, 199-222. http://dx.doi.org/10.1016/S0304-3932(02)00204-0

Krugman, P. R. (1991). Increasing returns and economic geography. The Journal of Political Economy, 99, 483-499. http://dx.doi.org/10.1086/261763

Krugman, P. R. (1998). What's new about the "New Economic Geography”. Journal of Political Economy, 14, 7-17.

Mandelbrot, B. (1963). The variation of certain speculative prices. Journal of Business, 36, 394-419. http://dx.doi.org/10.1086/294632

Martinez Oliva, J. C. (2009). Riunificazione intertedesca e politiche per la convergenza (Inter-German reunification and convergence polici- es), Questioni di Economia e Finanza (Occasional papers) (Issues of economics and finance (Occasional papers)), Banca d'Italia, 51.

Myrdal, K. G. (1957). Economic theory and under-developed regions. London: Gerald Duckworth.

Paolilli, A. L. (2008). Development and crisis in ancient Rome: The role of Mediterranean trade. Historical Social Research. An International Journal for the Application of Formal Methods to History, 33, 274-289.

Paolilli, A. L. (2011). Divari economici territoriali e processi di finanziarizzazione dell'economia. Il caso del Mezzogiorno nello scenario europeo del dopo Maastricht (Territorial economic disparity and processes of financing of the economy. The Mezzogiorno in the postMaastricht European scenario). PhD Thesis, Lecce: Salento University.

Paolilli, A. L. (2011). Altruism, selfishness and social cohesion. Sociology Mind, 1, 145-150.

Paolilli, A. L., \& Pollice, F. (2011). Trajectories of state formation in Eurasia: A discussion. Historical Social Research. An International Journal for the Application of Formal Methods to History, 36, 343371.

Paolilli, A. L., \& Pollice, F. (2011). Finance and centre-periphery dynamics: A model. iBusiness, 3, 248-261. http://dx.doi.org/10.4236/sm.2011.14018

Scheidel, W. (2007). The "First Great Divergence": Trajectories of postancient formation in eastern and western Eurasia. Princeton/Stanford: Working Papers in Classics.

Spratt, S. (2009). Development finance, debates, dogmas and new directions. London and New York: Routledge.

Vita, C. (2006-2007). Economie dualistiche e processi cumulativi di divergenza. Il dibattito sui Mezzogiorni d'Europa (Dualistic economies and cumulative processes of divergence. The debate on Europe's South). PhD Thesis, Benevento: Sannio University. 